\title{
Differential expression of genes mapping to recurrently abnormal chromosomal regions characterize neuroblastic tumours with distinct ploidy status
}

\author{
Cinzia Lavarino ${ }^{1}$, Idoia Garcia ${ }^{1}$, Carlos Mackintosh ${ }^{4}$, Nai-Kong V Cheung ${ }^{5}$, \\ Gema Domenech7, José Ríos ${ }^{7}$, Noelia Perez², Eva Rodríguez¹, Carmen de \\ Torres $^{1}$, William L Gerald ${ }^{6}$, Esperanza Tuset ${ }^{3}$, Sandra Acosta ${ }^{1}$, Helena Beleta ${ }^{1}$, \\ Enrique de Álava ${ }^{4}$ and Jaume Mora*1
}

\begin{abstract}
Address: ${ }^{1}$ Developmental Tumour Biology Laboratory, Hospital Sant Joan de Déu, Fundació Sant Joan de Déu, Barcelona, Spain, 2 Pathology, Hospital Sant Joan de Déu, Fundació Sant Joan de Déu, Barcelona, Spain, ${ }^{3}$ Hematology, Hospital Sant Joan de Déu, Fundació Sant Joan de Déu, Barcelona, Spain, ${ }^{4}$ Molecular Pathology Laboratory, Centro de Investigación del Cáncer-IBMCC (USAL-CSIC), Salamanca, Spain, ${ }^{5}$ Department of Pediatrics, Memorial Sloan-Kettering Cancer Centre, New York, USA, ${ }^{\circ}$ Pathology, Memorial Sloan-Kettering Cancer Centre, New York, USA and ${ }^{7}$ Unit of Biostatistics and Epidemiology, Universitat Autònoma, Barcelona, Spain

Email: Cinzia Lavarino - clavarino@fsjd.org; Idoia Garcia - igarcia@fsjd.org; Carlos Mackintosh - cmackintosh@usal.es; Nai-

Kong V Cheung - cheungn@ @mskcc.org; Gema Domenech - gema.domenech@h1.org.es; José Ríos - jose.rios@uab.es;

Noelia Perez - nperezm@hsjdbcn.org; Eva Rodríguez - erodriguez@fsjd.org; Carmen de Torres - cdetorres@hsjdbcn.org;

William L Gerald - geraldw@mskcc.org; Esperanza Tuset - etuset@hsjdbcn.org; Sandra Acosta - sacosta@fsjd.org;

Helena Beleta - hbeleta@fsjd.org; Enrique de Álava - edealava@usal.es; Jaume Mora* - jmora@hsjdbcn.org

* Corresponding author
\end{abstract}

Published: 13 August 2008

BMC Medical Genomics 2008, I:36 doi:10.1 186/1755-8794-1-36

This article is available from: http://www.biomedcentral.com/I755-8794/I/36

(c) 2008 Lavarino et al; licensee BioMed Central Ltd.

This is an Open Access article distributed under the terms of the Creative Commons Attribution License (http://creativecommons.org/licenses/by/2.0), which permits unrestricted use, distribution, and reproduction in any medium, provided the original work is properly cited.
Received: 4 March 2008

Accepted: 13 August 2008

\begin{abstract}
Background: Neuroblastic tumours (NBTs) represent a heterogeneous spectrum of neoplastic diseases associated with multiple genetic alterations. Structural and numerical chromosomal changes are frequent and are predictive parameters of NBTs outcome. We performed a comparative analysis of the biological entities constituted by NBTs with different ploidy status.

Methods: Gene expression profiling of 49 diagnostic primary NBTs with ploidy data was performed using oligonucleotide microarray. Further analyses using Quantitative Real-Time Polymerase Chain Reaction (Q-PCR); array-Comparative Genomic Hybridization (aCGH); and Fluorescent in situ Hybridization (FISH) were performed to investigate the correlation between aneuploidy, chromosomal changes and gene expression profiles.

Results: Gene expression profiling of 49 primary near-triploid and near-diploid/tetraploid NBTs revealed distinct expression profiles associated with each NBT subgroup. A statistically significant portion of genes mapped to Ip36 $(P=0.01)$ and I7pI3-q2I $(P<0.0001)$, described as recurrently altered in NBTs. Over $90 \%$ of these genes showed higher expression in near-triploid NBTs and the majority are involved in cell differentiation pathways. Specific chromosomal abnormalities observed in NBTs, Ip loss, I7q and whole chromosome 17 gains, were reflected in the gene expression profiles. Comparison between gene copy number and expression levels suggests that differential expression might be only partly dependent on gene copy number. Intratumoural clonal
\end{abstract}


heterogeneity was observed in all NBTs, with marked interclonal variability in near-diploid/ tetraploid tumours.

Conclusion: NBTs with different cellular DNA content display distinct transcriptional profiles with a significant portion of differentially expressed genes mapping to specific chromosomal regions known to be associated with outcome. Furthermore, our results demonstrate that these specific genetic abnormalities are highly heterogeneous in all NBTs, and suggest that NBTs with different ploidy status may result from different mechanisms of aneuploidy driving tumourigenesis.

\section{Background}

Neuroblastic tumours (NBTs) are one of the most common neoplasms in childhood, accounting for approximately $40 \%$ of solid tumours encountered in the first four years of life [1]. NBTs are heterogeneous in terms of their biological, genetic and morphological characteristics and exhibit marked diverse clinical behaviours.

The biological bases of these processes are poorly understood. There is an apparent link between NBTs aggressiveness and specific genetic aberrations (i.e., MYCN amplification, chromosome deletions of 1p36, 11q23, $14 \mathrm{q} 32$ or 19q13.3; gain of $17 \mathrm{q}$ and near-diploid/tetraploid DNA content), indicating that specific genetic alterations are present in individual categories of NBTs and likely contribute to clinical outcome [2-4].

Abnormal cellular DNA content is ubiquitous in cancer and has been linked to the rate of cell proliferation, cell differentiation, and prognosis in a variety of tumour cell types. In contrast to most other tumours, hyperploidy confers a favourable prognosis in NBTs [5], acute lymphoblastic leukemia [6], and rhabdomyosarcoma [7]. Non-metastatic loco-regional NBTs (stages 1, 2 and 3) often show modal chromosomal numbers in the near-triploid range (58 to 80 modal chromosome number) and few structural aberrations [5]. On the other hand, karyotypes of metastatic NBTs are commonly near-diploid (44 to 57 chromosomes) or near-tetraploid (81-103 chromosomes) with structural changes [5].

The presence of specific and recurrent chromosomal alterations in NBTs suggests that gene copy number abnormalities represent a major biologically relevant event, which contributes to NBT growth and survival. The aim of the current study was to gain further insight into the difference in gene expression of distinct biological entities within NBTs defined by the ploidy status.

\section{Methods}

\section{Patients and samples}

Forty-nine diagnostic primary NBT specimens (24 stages 1, 2, and 3; 7 stage $4 \mathrm{~s}$; and 18 stage 4) obtained from patients diagnosed and treated at MSKCC were selected for gene expression profiling (Table 1). Risk assessment was defined by the INSS staging classification, the MSKCC biological risk stratification criteria, and the COG clinical staging criteria. NBT stages 1, 2, 3 and 4s were treated without use of cytotoxic therapy, when possible, according to MSKCC protocols. Stage 4 NBTs patients were treated according to N5, N6 or N7 protocols. This study was approved by the MSKCC and HSJD Institutional Review Boards and informed consent was obtained before collection of all samples.

Twenty-one samples (9 stages 1, 2, and 3; 1 stage 4s; and 11 stage 4 ) of the original MSKCC NBT cohort included in the gene profiling analysis and an independent set of 25 primary NBT specimens (12 stage 1, 2, and 3, 2 stage 4s, and 11 stage 4) obtained at diagnosis from 3 Spanish institutions (HSJD, Barcelona; Hospital La Paz, Madrid; and Department of Pathology, University of Valencia) were available for validation analyses (Table 1). Normal control DNA was obtained from the National DNA Bank of Spain.

All tumour-specimens were evaluated by the same pathologists (WG and NP) to assess tumour cell content, only tumours with $>70 \%$ were included in the study.

\section{DNA content analysis}

The modal DNA content was determined by flow cytometry DNA analysis on nuclei isolated from paraffin sections using the method of Hedley modified [8]. DNA index (DI) was expressed as the ratio of tumour DNA content/ standard DNA fluorescence; near-diploid DI = 0.90-1.20; near-triploid DI $=1.21-1.75$; near-tetraploid DI $=1.76-$ 2.20 .

\section{Gene expression profiling}

Gene expression profiling was performed of 49 primary NBT samples (22 near-triploid, 23 near-diploid and 4 near-tetraploid) using Affymetrix GeneChip Human Genome U95 $\mathrm{Set}^{\mathrm{TM}}$ Arrays, as previously reported [9]. Microarray data and sample annotations have been deposited in the caArray database http://caar raydb.nci.nih.gov/caarray/. 
Table I: Clinical and Biological characteristics of patients with Neuroblastoma evaluated according to tumour ploidy status.

\begin{tabular}{|c|c|c|c|c|c|c|c|c|}
\hline Case number & ploidy & Age & INSS stage & $\begin{array}{c}\text { MYCN } \\
\text { amplification }\end{array}$ & Disease Status & Survival Status & $\begin{array}{l}\text { microarray } \\
\text { analysis }\end{array}$ & $\begin{array}{c}\text { validation } \\
\text { analysis }\end{array}$ \\
\hline & & $\begin{array}{l}<12 m=0 \\
>12 m=1\end{array}$ & $\mathrm{I}, 2,3,4 \mathrm{~s}=0 ; 4=\mathrm{I}$ & & & & & \\
\hline I & near-3n & I & 0 & NA & NP & $A$ & $Y$ & $Y$ \\
\hline 2 & near-3n & 1 & 0 & NA & NP & $A$ & $Y$ & . \\
\hline 3 & near-3n & 1 & 0 & NA & NP & $A$ & Y & $Y$ \\
\hline 4 & near-3n & 0 & 0 & NA & NP & $A$ & $Y$ & . \\
\hline 5 & near-3n & 0 & 0 & NA & NP & $A$ & Y & $Y$ \\
\hline 6 & near-3n & 0 & 0 & NA & NP & $A$ & $Y$ & . \\
\hline 7 & near-3n & 0 & 0 & NA & $P$ & $A$ & Y & . \\
\hline 8 & near-3n & 0 & 0 & NA & $P$ & A & $Y$ & . \\
\hline 9 & near-3n & 0 & 0 & NA & NP & A & Y & . \\
\hline 10 & near-3n & 0 & 0 & NA & NP & A & Y & . \\
\hline 11 & near-3n & I & 0 & NA & NP & $A$ & Y & $Y$ \\
\hline 12 & near-3n & 0 & 0 & NA & NP & A & Y & . \\
\hline 13 & near-3n & 1 & 1 & NA & $P$ & $D$ & Y & . \\
\hline 14 & near-3n & 1 & 0 & NA & NP & $A$ & $Y$ & . \\
\hline 15 & near-3n & 0 & 0 & NA & NP & $A$ & $Y$ & $Y$ \\
\hline 16 & near-3n & 0 & 0 & NA & NP & A & $Y$ & . \\
\hline 17 & near-3n & 0 & 0 & NA & $\mathrm{P}$ & A & Y & $Y$ \\
\hline 18 & near-3n & 1 & 1 & NA & $P$ & $D$ & $Y$ & $Y$ \\
\hline 19 & near-3n & 1 & 0 & NA & NP & A & $Y$ & . \\
\hline 20 & near-3n & 1 & 0 & NA & NP & A & $Y$ & $Y$ \\
\hline 21 & near-3n & 0 & 0 & NA & $P$ & A & Y & . \\
\hline 22 & near-3n & 1 & 0 & NA & $P$ & $D$ & $Y$ & $Y$ \\
\hline 23 & near-3n & 0 & 0 & NA & NP & $A$ & . & $Y$ \\
\hline 24 & near-3n & 0 & 0 & NA & NP & $A$ & . & $Y$ \\
\hline 25 & near-3n & 0 & 0 & NA & NP & A & . & $Y$ \\
\hline 26 & near-3n & 0 & 0 & NA & NP & A & . & $Y$ \\
\hline 27 & near-3n & 1 & 0 & NA & NP & A & . & $Y$ \\
\hline 28 & near-3n & 1 & 0 & NA & NP & A & . & $Y$ \\
\hline 29 & near-3n & 1 & 0 & NA & NP & $A$ & . & $Y$ \\
\hline 30 & near-3n & 1 & 0 & NA & NP & A & . & $Y$ \\
\hline 31 & near-3n & 0 & 1 & NA & NP & $A$ & . & $Y$ \\
\hline 32 & near-3n & 0 & 0 & NA & NP & A & . & $Y$ \\
\hline 33 & near-3n & 1 & I & NA & $P$ & $A$ & . & $Y$ \\
\hline 34 & near-3n & 0 & 0 & NA & NP & $A$ & . & $Y$ \\
\hline 35 & near-3n & 0 & 0 & NA & $P$ & $D$ & . & $Y$ \\
\hline 36 & near-3n & 0 & 0 & NA & NP & A & . & $Y$ \\
\hline 37 & near-3n & 0 & 0 & NA & NP & A & . & $Y$ \\
\hline 38 & near-2n & I & I & A & NP & A & Y & $Y$ \\
\hline 39 & near $-2 n$ & 1 & 1 & $A$ & $P$ & $D$ & $Y$ & Y \\
\hline 40 & near-2n & I & 0 & NA & $P$ & $D$ & $Y$ & . \\
\hline 41 & near- $2 n$ & 1 & 1 & A & $P$ & $\mathrm{D}$ & $Y$ & $\dot{Y}$ \\
\hline 42 & near $-2 n$ & 1 & 1 & A & $P$ & $A$ & $Y$ & $Y$ \\
\hline 43 & near- $2 n$ & I & i & NA & NP & $A$ & $Y$ & $Y$ \\
\hline 44 & near-2n & 1 & I & NA & $P$ & $D$ & $Y$ & . \\
\hline 45 & near- $2 n$ & 1 & 1 & $A$ & $P$ & $D$ & $Y$ & . \\
\hline 46 & near- $2 n$ & 1 & 1 & NA & NP & $A$ & $Y$ & . \\
\hline 47 & near- $2 n$ & 1 & 0 & NA & $P$ & $D$ & $Y$ & . \\
\hline 48 & near $-2 n$ & I & 0 & NA & $P$ & $\mathrm{D}$ & $Y$ & . \\
\hline 49 & near- $2 n$ & 0 & I & A & NP & A & $Y$ & . \\
\hline 50 & near $-2 n$ & 0 & 0 & NA & $N P$ & A & $Y$ & Y \\
\hline 51 & near-2n & 0 & 0 & NA & $P$ & A & $Y$ & . \\
\hline 52 & near $-2 n$ & 1 & 1 & A & $P$ & D & $Y$ & $\dot{Y}$ \\
\hline 53 & near- $2 n$ & I & 0 & A & NP & A & $Y$ & $Y$ \\
\hline 54 & near-2n & I & 0 & NA & NP & A & $Y$ & . \\
\hline
\end{tabular}


Table I: Clinical and Biological characteristics of patients with Neuroblastoma evaluated according to tumour ploidy status. (Continued)

\begin{tabular}{|c|c|c|c|c|c|c|c|c|}
\hline 55 & near-2n & $T$ & $T$ & NA & $P$ & $\mathrm{D}$ & $\bar{Y}$ & $\bar{Y}$ \\
\hline 56 & near-2n & 0 & 0 & NA & $P$ & $A$ & $Y$ & . \\
\hline 57 & near- $2 n$ & 0 & 0 & NA & NP & A & $Y$ & . \\
\hline 58 & near- $2 n$ & I & I & NA & $P$ & $D$ & Y & . \\
\hline 59 & near- $2 n$ & I & i & NA & $P$ & $D$ & Y & $Y$ \\
\hline 60 & near- $2 n$ & I & 0 & NA & $P$ & $D$ & $Y$ & . \\
\hline 61 & near $-2 n$ & 0 & 0 & NA & NP & $A$ & . & $Y$ \\
\hline 62 & near- $2 n$ & I & 1 & NA & $P$ & D & . & $Y$ \\
\hline 63 & near-2n & I & I & $A$ & $P$ & $D$ & . & $Y$ \\
\hline 64 & near- $2 n$ & I & I & NA & NP & $A$ & . & $Y$ \\
\hline 65 & near- $2 n$ & i & 1 & NA & $P$ & D & . & $Y$ \\
\hline 66 & near $-2 n$ & 0 & 0 & A & NP & $A$ & . & $Y$ \\
\hline 67 & near- $2 n$ & I & 1 & A & $P$ & $D$ & . & $Y$ \\
\hline 68 & near $-2 n$ & 1 & 1 & NA & $P$ & $A$ & . & $Y$ \\
\hline 69 & near $-4 n$ & I & 0 & NA & NP & $A$ & $Y$ & . \\
\hline 70 & near-4n & 0 & I & $A$ & $P$ & $D$ & $Y$ & $Y$ \\
\hline 71 & near-4n & I & I & NA & NP & $A$ & $Y$ & $Y$ \\
\hline 72 & near-4n & 0 & 1 & NA & $P$ & $A$ & $Y$ & . \\
\hline 73 & near- $-4 n$ & I & 0 & A & $P$ & $D$ & . & $Y$ \\
\hline 74 & near- $4 \mathrm{n}$ & I & 1 & $A$ & $P$ & $\mathrm{D}$ & . & $Y$ \\
\hline
\end{tabular}

MYCN amplification status: $\mathbf{N A}=$ not amplified, $\mathbf{A}=$ amplified. Disease status: $\mathbf{N P}=$ no disease progression, $\mathbf{P}=$ disease progression. Survival status: $\mathbf{A}=$ alive, $\mathbf{D}=$ dead. Microarray and validation analyses: $Y=$ cases analyzed.

\section{Differential gene expression analysis}

Genes with high variability within samples were selected by pair-wise comparison analyses performed by adjusting the type-I error for multiple tests (Step-down permutation (SDP) [10], and False Discovery Rate (FDR) [11]), and with no type-I error adjustment (Raw method). The cutoff Family-wise error applied to select significant genes by means of the T-test for independent data, a univariate screening supervised procedure, was equivalent for all three methods: $<0.1,<0.05$ and $<0.01$. Hierarchical clustering analyses were performed for the differentially expressed genes for all the methods of adjustment of Type-I error and cut-off of P-values, using a multivariate unsupervised method, taking into account the relationship between gene expressions. Fisher's exact test and 95\% bilateral confidence interval using Wilson method were used to evaluate the proportion with which chromosomes were represented in the selected gene sets in comparison to chromosome representation within the Affymetrix GeneChip U95Av2. Statistical analyses were performed using SAS 9.1 and JMP 5.1 (SAS Institute Inc) for Windows and CIA 2.1.1.

\section{Gene Ontology annotation categories}

Gene Ontology (GO) annotation categories were analyzed using explore GeneOntology (eGOn v2.0) in Gene Tools web service http://www.genetools.no to create a biological profile of the differentially expressed genes. Overrepresented GO terms were determined statistically by Fisher's exact test $(P<0.01)$ and adjusted FDR $<0.01$.

\section{Quantitative Real-time PCR (Q-PCR)}

Quantification of transcript levels using Q-PCR was performed of 13 genes located on chromosomes 1 and 17 (see Additional file 1). Concomitant quantification of gene copy number was performed for a set of these genes (see Additional file 1). MYCN gene copy number was analyzed by Q-PCR, and FISH when needed. Validation analyses were performed on 46 primary NBT specimens (see patients and samples).

Q-PCR reactions and quantification, using the $\Delta \Delta \mathrm{C}_{\mathrm{T}}$ relative quantification method, were performed on an $\mathrm{ABI}$ Prism 7000 Sequence Detection System using TaqMan ${ }^{\circledR}$ Assay-on-Demand Gene Expression products, according to the manufacturer's protocols (Applied Biosystems, US). All experiments included no template controls and were performed in duplicate and repeated twice independently. Transcript levels were measured relative to 3 normal tissue samples (adrenal gland, lymph node and bone marrow) and normalized to TATA box binding protein (TBP), hypoxantine phosphoribosyltransferase 1 (HPRT1) and succinate dehydrogenase complex, subunit A (SDHA) expression values. Endogenous control genes were chosen on the basis of recent publications regarding accurate normalization of real-time quantitative RT-PCR in primary neuroblastoma $[12,13]$. These genes are reported within the most stable set of endogenous control genes. Gene copy number quantification was performed as reported previously [14]. Gene copy number was calculated relative to placental DNA using the B-Cell maturation factor (BCMA) as reference gene. The validity of BCMA as reference gene in our cohort of NBTs was determined by copy 
number ratio: $\mathrm{BCMA}_{\mathrm{NB} \text { tumour test sample }} / \mathrm{BCMA}_{\text {placenta calibra- }}$ tor sample. The ratio measured was equal to 1.0016; (tumour DNA $1.0012 \pm 0.13 \mathrm{SD}) /($ placental DNA $0.9996 \pm 0.05)$.

\section{Fluorescent in situ hybridization (FISH)}

FISH was assayed on $4 \mu \mathrm{m}$ sections of Tissue-Micro-Array (TMA) of formalin-fixed paraffin-embedded NBT samples corresponding to the validation set, and partially matching the MSKCC series described above. Tissue microarrays included only tumour areas showing $>90 \%$ of tumour cells. Sections were washed with $2 \times$ SSC buffer and fixed in $4 \%$ paraformaldehyde in PBS. DNA-probes, CEP 17 Alpha (Ref: 32-112017;Vysis, IL, USA) LSI p53 (Ref:30190008;Vysis) and/or LSI 1p36 (Ref:30-231004;Vysis), were denatured at $73^{\circ} \mathrm{C}, 5 \mathrm{~min}$., applied to tissue sections and simultaneously denatured using the Hybridizer (DAKO) at $90^{\circ} \mathrm{C}, 4 \mathrm{~min}$. Hybridization was performed for $16 \mathrm{~h}$ at $37^{\circ} \mathrm{C}$ in a humid chamber. Slides were then washed with Buffer post-hybridization (Master Diagnostica, Granada, Spain) and stained with DAPI (6-diamidino-2-phenylindole) and mounted with Vectashield H1000 medium (Vector). One hundred nuclei were evaluated for each core. Results were recorded as percentage of nuclei present in the sample having each probe signal pattern. Cell populations $<5 \%$ of abnormal cells were not scored as significant. Microscope Magnification $\times 1000$.

\section{Array comparative genomic hybridization (aCGH)}

Whole genome BAC-aCGH studies were performed using the Sanger $1 \mathrm{Mb}$ clone set (kindly provided by Dr. K. Szuhai LUMC, The Netherlands). BAC/PAC clones were added to increase resolution for regions of interest: full genomic coverage clones for chromosome 17 (CHORI) and chromosome 11 (BAC/PAC isolated DNA, kindly provided by Dr. J. San Miguel, CIC, Salamanca), and 19 q13 enriched medium-coverage set (Invitrogen, CA, USA and kindly provided by Dr. JC Cigudosa, CNIO, Spain). BAC DNA was extracted, amplified by DOP and Aminolinking-PCR and spotted in triplicate onto Codelink slides (Amersham Biosciences, GE, USA).

Tumour and reference DNA (an equimolar DNA pool from 40 healthy donors, obtained from the Spanish National DNA Bank) was Cy5/Cy3-dCTP (Amersham, GE) labelled using a non-commercial Random Priming kit composed by Random Octamers dissolved in Eppicentre Exo-Minus Klenow buffer, a dNTPs mix depleted in dCTP and Exo-Minus Klenow enzyme (Eppiocentre). Labelled DNA was purified through Illustra G-50 Microspin Columns, mixed and then precipitated along with Cot DNA (Roche). Hybridization was performed for 48 hours at $42^{\circ} \mathrm{C}$ and probe excess removed.

\section{Imaging acquisition and data analysis}

$\log _{2}$ data was acquired using Axon 4000B scanner and GenePix software. Normalization was done with GenePix software using the mean of the median of ratios of all the autosomal features in the array, excluding those removed by the quality flagging scripts. Gpr files were subsequently processed with Bioconductor packages (CRAN) incorporating scripts for removing $\mathrm{SD}>0.2$ and GenePix flagged spots. DNA copy algorithm and Merge Levels scripts (both implemented in snap CGH package) were applied for segmentation of the data. A graded colour code adjusted to the $\log _{2}$ rank of each individual plot was assigned to define the segments found by the applied algorithm. Universal threshold cut-off values for defining gain/loss were not applied because of subpopulation clonal heterogeneity, ploidy, and percentage of neuroblastic cells, which varied from one sample to another. Due to this, plots were evaluated independently by visual examination and results were depicted using a graded colour code adjusted to the $\log _{2}$ rank of each plot, assigning a colour grade to every segment found by the segmentation algorithm.

\section{Results}

\section{Differential gene expression analysis}

Gene expression analysis was performed on a spectrum of 49 NBTs with varying DNA content (22 near-triploid, 23 near-diploid and 4 near-tetraploid). Owing to reduced number of near-tetraploid cases included in this study and taking into account the reported biological and clinical similarities with near-diploid NBTs $[15,16]$, near-diploid and near-tetraploid NBTs were combined in one group. Pair-wise comparison analyses of near-triploid $(\mathrm{n}=22)$ versus near-diploid/tetraploid $(\mathrm{n}=27)$ NBTs revealed small sets of differentially expressed genes when using a stringent correction for multiple sampling, (6 genes [FDR $<0.01$ ] and 12 genes [SDP < 0.1]) (see Additional file 2). Interestingly, all genes showing a higher expression in the near-triploid group mapped to chromosome 17 (see Additional file 2). Less stringent multiple testing corrections selected a larger set of differentially expressed genes, ( 51 genes [FDR < 0.05] (Fig. 1) and 254 genes [FDR < 0.1 ] (see Additional file 2). Again, this resulted in a statistically significant proportion of genes mapping to chromosomes with described recurrent abnormalities in NBTs; chromosome $1(\mathrm{p}=0.01)$ and chromosome 17 ( $\mathrm{p}<0.0001)$ (Fig. 1). Chromosomal region specificity was observed since the majority of chromosome 1 and 17 differentially expressed genes spread over 1p36-p22.1 and 17p1317 q21 (Fig. 1; see Additional file 2). The majority showed higher expression in near-triploid NBTs; $92 \%$ (CI: $78 \%$ to $97 \%$ ) of chromosome 1 genes and $91 \%$ (CI: $76 \%$ to $96 \%$ ) of chromosome 17 (see Additional file 2). Only 8\% (CI: $2 \%$ to $21 \%$ ) probe sets for genes located on chromosome 1, ENO1 (1p36.2), CCT3 (1q23) and C1orf107 (1q32.2), and $9 \%$ (CI: $3 \%$ to $23 \%$ ) for genes on chromosome 17 , 


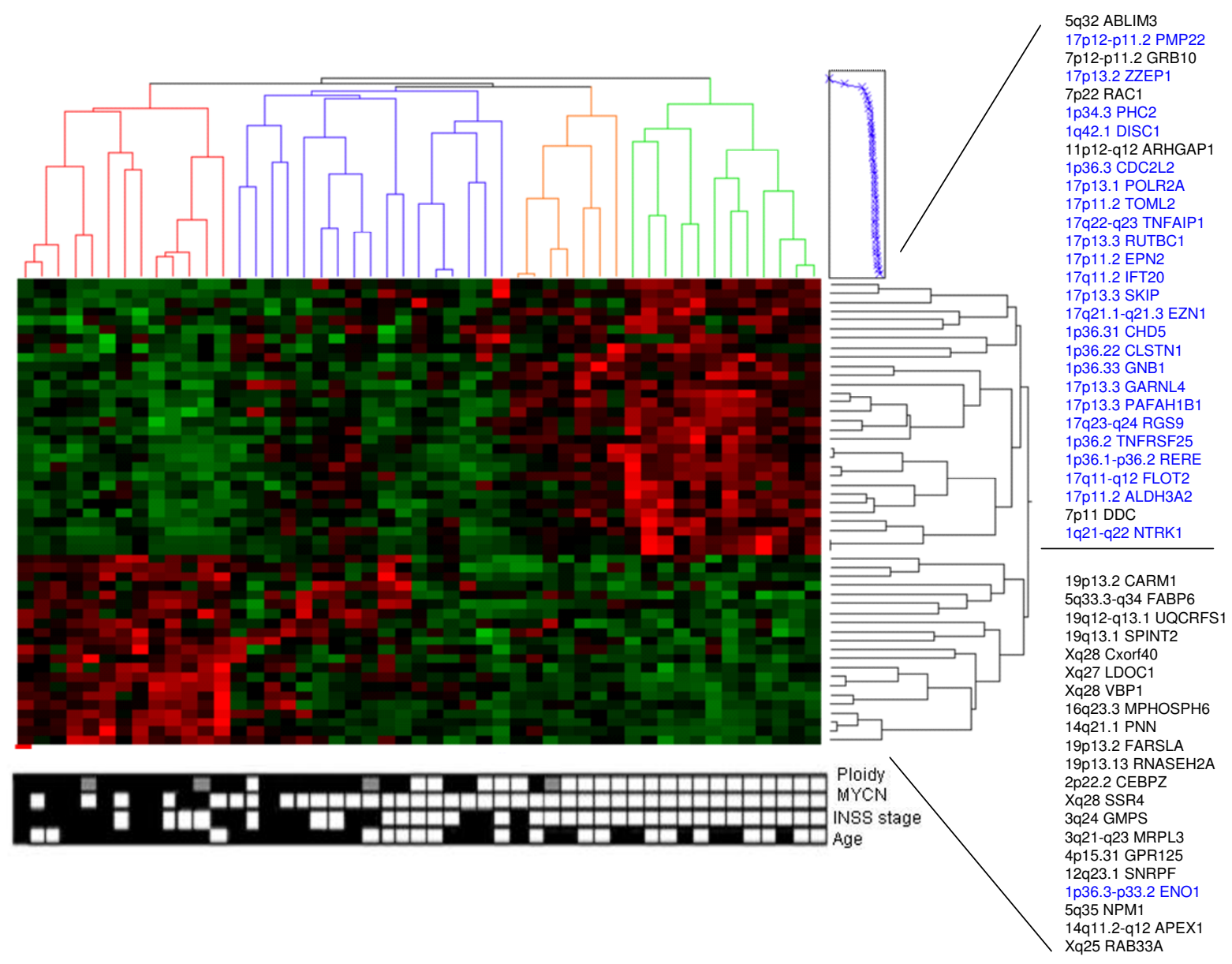

Figure I

A heatmap illustrating the distinct expression profiles of 49 NB primary tumours with varying ploidy status. Gene expression profiles visualized according to 5I differentially expressed genes [FDR < 0.05]. (Right) Gene dendrogram is divided in 2 main gene clusters. Top cluster: genes displaying higher expression in near-triploid tumours; a statistically significant proportion of genes map to chromosome I $(p=0.0 \mathrm{I})$ and chromosome I7 $(p<0.000 \mathrm{I})$ (Blue). Bottom cluster: genes with higher expression in near-diploid/tetraploid NBTs. (Bottom) Filled in boxes: Ploidy: black = near-diploid, empty white boxes = near-triploid, grey = near-tetraploid NBTs; MYCN: black = amplified, white = not amplified; Age: black > 12 months, white < I2 months; INSS: black = Stage 4 NBTs, white = stages I, 2, 3, and 4S.

MAC30 (17q11.2) and NME1 (17q21.3), showed a higher expression within near-diploid/tetraploid NBTs.

The Gene Ontology biological profile of genes with higher expression in near-diploid/tetraploid NBTs showed enrichment for genes related to protein, macromolecular and nucleic acid biosynthesis, such as, NME1, ATP5I, ATP5C1, NME4, TYMS and GMPS. Whereas, near-triploid tumours included genes involved in vesicle mediated transport, cell communication, signal transduction, nervous system development and regulation of small GTPase mediated signal transduction. A large portion of these genes mapped to chromosomes 1 and 17 (60-100\%), among these RERE, CHD5, CLCN6, CDC42BPA, NTRK1, ARHGEF11, PMP22, VAMP2, GARNL4, MAP2K4 and FLOT2.

\section{Quantitative Real-time Polymerase Chain Reaction (Q- PCR)}

Quantification of transcript levels of 13 differentially expressed genes, located mainly on the chromosomal regions 1 p36 and 17p13-q21, was performed on two separate groups of NBT specimens: 21 primary NBTs from the original MSKCC cohort as well as on an independent set 
of 25 NBTs (Table 1). Expression levels identified by QPCR confirmed the microarray data in both sets of NBTs (Fig. 2A, B and 2C).

Four genes located on chromosomes 1 and 17 were further analyzed for gene copy number by DNA Q-PCR analysis in 27 cases (Tables 2 and 3; see Additional file 3). Near-triploid NBTs $(n=13)$ showed, both for chromosome 1 and 17, fold values consistently higher $(\geq 1.3$ fold) than normal reference gene values, and were considered to represent a minimum trisomic gene copy number. Only case \# 2 (Table 2; see Additional file 3 ) showed 0.81.1 -fold values reflecting a possible loss of $1 \mathrm{p} 36$, subsequently confirmed by FISH and aCGH results. Near-diploid/tetraploid NBTs $(\mathrm{n}=13)$ displayed a wider range of values (0.5-2.7-fold), indicative of losses and gains within a more heterogeneous clonal population, as shown by FISH results. Tumour clonal heterogeneity may often confound analyses performed on the bulk of the tumour specimen and could explain some discrepancies between ploidy and gene copy number.

Comparison between DNA gene copy number and expression levels (Fig. 3) revealed an overall linear correlation for those analyzed genes that displayed in the microarray analysis higher expression levels in near-triploid NBTs. Conversely, NME1 gene, as from microarray results, showed low expression values, closer to the disomic reference sample expression, in near-triploid NBTs, and high fold increase in mRNA levels in near-diploid and tetraploid cases.

\section{Fluorescent in situ hybridization (FISH)}

Interphase FISH using the DNA probes LSI 1p36 and LSI 1q25 was performed on 13 primary NBTs drawn from the HSJD cohort; four cases were not evaluable (Table 2). According to chromosome 1 status, near-triploid and near-diploid/tetraploid NBTs were characterized by intratumoural heterogeneous cell population content. Only 1 case showed uniform distribution of probe signals within cells of the tumour specimen (case \#10, Table 2). All but one of the near-triploid NBTs were constituted of clonal populations with two LSI 1p36 and LSI 1q25 signals (2:2) and/or three (3:3) DNA probe signal, ranging from 40$60 \%$ and $40-100 \%$ of the cells, respectively. Case \# 2 was the only near-triploid NBT that exhibited a chromosome $1 \mathrm{p} 36$ loss in $30 \%$ of cells, confirmed by aCGH and QPCR. Even higher intratumoural heterogeneity was observed in near-diploid/tetraploid NBTs.

Chromosome 17 FISH using centromeric CEP 17 and LSI p53 (17p13.1) DNA probes, was performed on 53 primary NBTs (13 cases from the HSJD cohort, Table 3, and 40 cases from MSKCC, Table 4). Based on chromosome 17 status, near-triploid tumours were constituted of two
(2 CEP 17 and 2 LSI p53 signals, 2:2), three (3:3) and four (4:4) chromosome 17 signals clonal populations that ranged from $10-55 \%, 24-70 \%$ and $7-45 \%$ of the cells, respectively. Near-diploid/tetraploid NBTs were composed by a more heterogeneous cell population, with a high incidence of chromosomal structural abnormalities. In a large portion of these tumours, alongside with the two $(2: 2)$ DNA probe signal clonal populations $(6 \%-$ $100 \%$ of cells), the aneuploid cell population counterpart constituted a significant and heterogeneous portion of cell population (Tables 3 and 4).

Intratumoural clonal heterogeneity was observed in all the FISH analyses (Fig. 4).

\section{Array comparative genomic hybridization (aCGH)}

Genome array CGH was performed for 13 cases, drawn from the HSJD validation set of NBTs, with complete FISH and Q-PCR analyses (Tables 2 and 3; Fig. 5). Near-triploid NBTs exhibited the highest incidence of specific chromosomal alterations, with consistent gain or loss of whole chromosomes, being chromosomes 7 and 17 the most frequently gained ( $83 \%$ and $100 \%$ cases, respectively), whilst, chromosomes 3, 4, 9, 14, 16 (50\% cases), and 19 (67\% NBTs) were among the most frequently lost, although the set of cases is not large enough for statistically significant results. Chromosome $1 \mathrm{p}$ loss was observed only in one case (case\# 2, Table 2), a near-triploid stage $4 \mathrm{~s}$ tumour.

Specific near-diploid/tetraploid copy number alterations were characterized by a more heterogeneous pattern of chromosomal aberrations than those of near-triploid, being partial chromosomal segment alterations much more frequent than in near-triploid tumours (Fig 5; see Additional file 4). Partial loss of $11 \mathrm{q}$ and partial gain of $17 \mathrm{q}$ were only observed in near-diploid/tetraploid samples and never in near-triploid NBTs. Chromosome 20 showed a common pattern being one of the most frequent gains both in near-diploid and near-triploid NBTs. MYCN amplification was absent in near-triploid cases and shared by near-diploid/tetraploid cases.

Further copy-number alterations that did not reach the maximum $\log _{2}$ values, but were clearly distinguishable in terms of segmentation algorithm, were detected in the array CGH plots and could reflect higher intratumoural clonal heterogeneity (data not shown).

\section{Discussion}

Aneuploidy is ubiquitous in cancer and has been linked to cell proliferation, cell differentiation and prognosis. The karyotypes of most tumours are aneuploid, meaning that chromosomes, which carry thousands of genes, are structurally rearranged, duplicated, broken or entirely missing. 
A

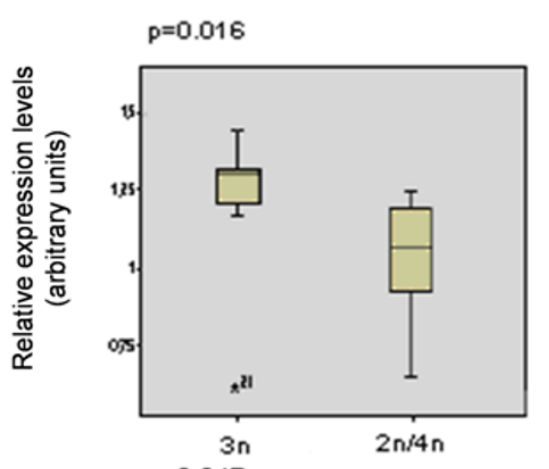

$p=0.047$
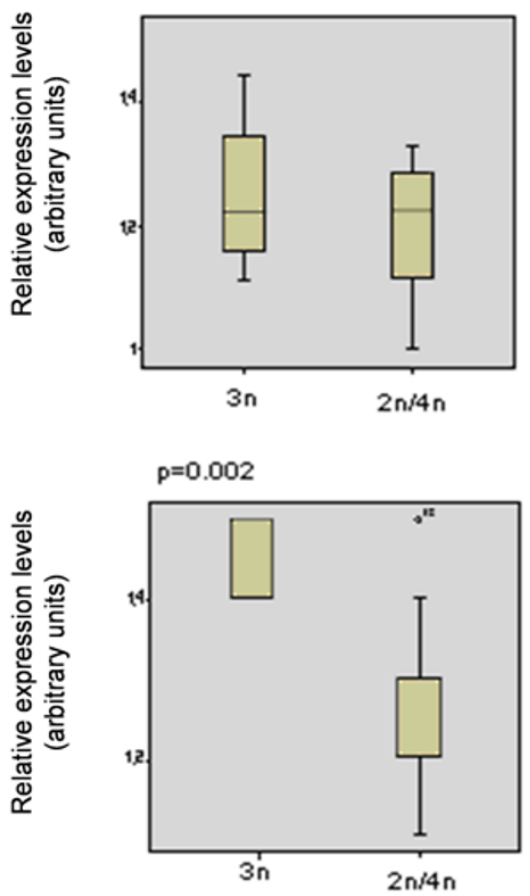

$p=0.004$

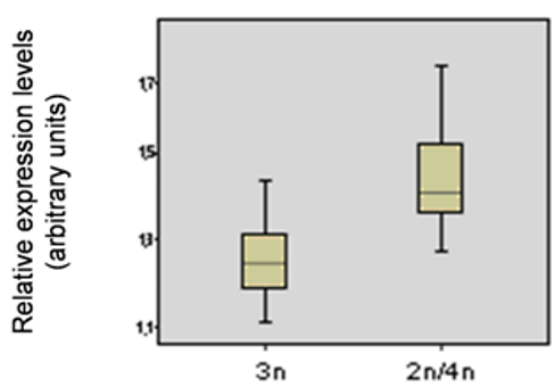

B
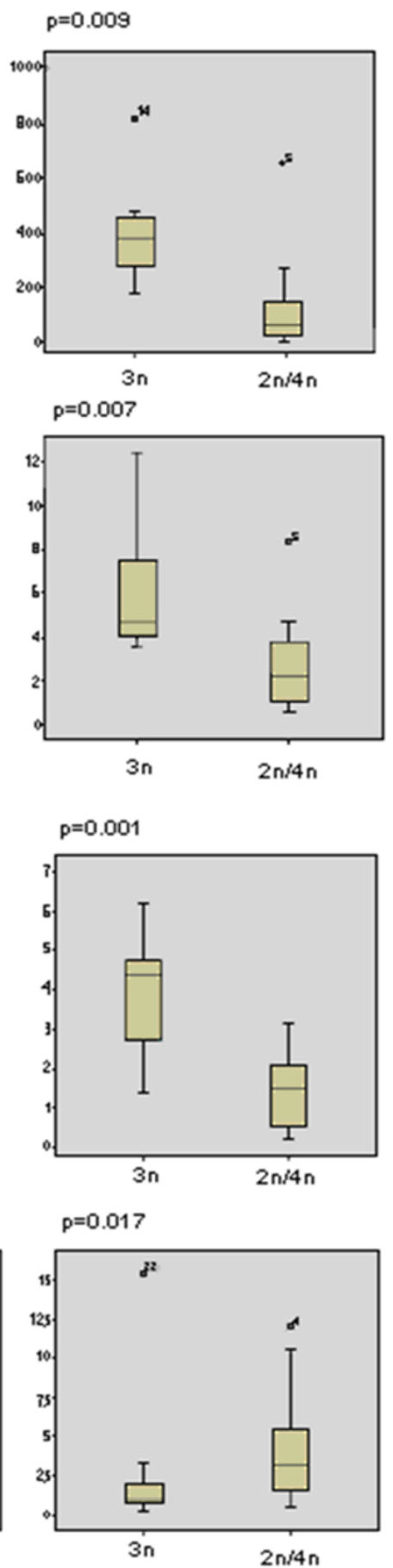

C

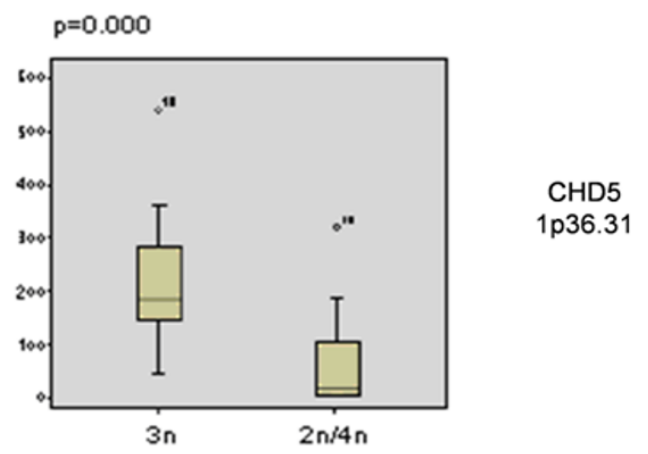

$p=0.002$

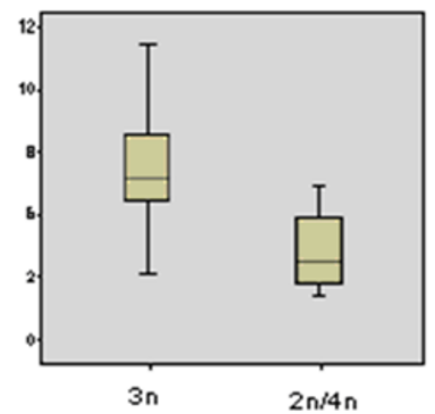

PTPRF

1p34-p32

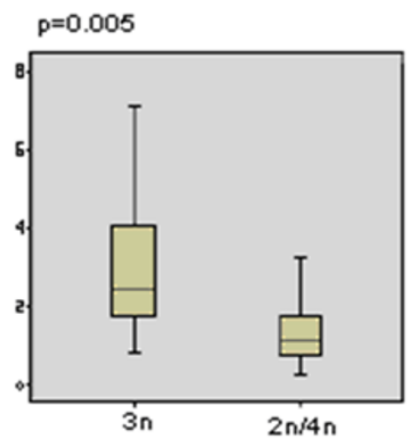

PAFAH1B1

$17 \mathrm{p} 13.3$

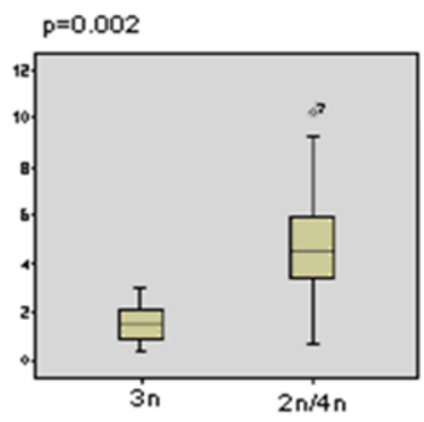

NME1

$17 q 21.3$

Figure 2

Quantitative real-time PCR validation of microarray gene expression data. Comparison of gene expression levels of 5 representative genes located on chromosomes I and 17. A. Microarray gene expression data in 49 NBT from MSKCC. Gene expression data were log-transformed and normalized to TBP expression levels; B. Q-PCR gene transcript quantification in 2I NBTs from MSKCC; C. Q-PCR gene transcript quantification in 25 NBTs from Spanish institutions. Results were compared by two-tailed independent-sample $t$ test using SPSS v.14.0 for Windows (SPSS, Chicago, IL). Expression data are shown as box plots (SPSS v. I 4.0). 
Table 2: Results of FISH, aCGH, Q-PCR analyses of chromosome I, displayed in relation to NBTs ploidy status

\begin{tabular}{|c|c|c|c|c|c|c|c|c|c|c|}
\hline \multirow[t]{2}{*}{$\begin{array}{c}\text { Case } \\
\text { Number }\end{array}$} & \multirow[t]{2}{*}{ Ploidy } & \multirow[t]{2}{*}{ MYCN } & \multirow{2}{*}{$\begin{array}{l}\text { FISH Chromosome } \\
\text { I } \\
\text { Cell \% (\#DNA probe } \\
\text { signals: LSI Ip36: LSI } \\
\text { Iq25) }\end{array}$} & \multicolumn{3}{|c|}{ a CGH Chr. I } & \multicolumn{2}{|c|}{$\begin{array}{l}\text { Q-PCR Gene copy No. } \\
\text { (fold change) }\end{array}$} & \multirow[t]{2}{*}{$\begin{array}{l}\text { Disease } \\
\text { Status }\end{array}$} & \multirow[t]{2}{*}{$\begin{array}{l}\text { Survival } \\
\text { Status }\end{array}$} \\
\hline & & & & $\mathrm{P}$ & cen & $q$ & $\begin{array}{c}\text { GNBI } \\
(\text { Ip36.33) }\end{array}$ & RERE (Ip36.I) & & \\
\hline 1 & near-3n & NA & n.e & G & G & G & 1.6 & 3.2 & NP & $A$ \\
\hline 2 & near-3n & NA & $\begin{array}{c}50(2: 2), 20(3: 3), 15 \\
(1: 3), 15(2: 3)\end{array}$ & $\mathrm{L}$ & - & - & 0.8 & I.I & NP & A \\
\hline 3 & near-3n & NA & $60(2: 2), 40(3: 3)$ & - & - & - & 1.5 & 2 & NP & A \\
\hline 4 & near-3n & NA & $5(2: 2), 95(3: 3)$ & G & G & G & 2.6 & 2.4 & NP & $A$ \\
\hline 5 & near-3n & NA & $40(2: 2), 60(3: 3)$ & - & - & - & 1.4 & 1.3 & NP & $A$ \\
\hline 6 & near-3n & NA & $50(2: 2), 50(3: 3)$ & G & G & G & 1.4 & 3 & NP & A \\
\hline 7 & near- $2 n$ & A & n.e. & $\mathrm{L}$ & - & - & 0.5 & 2.2 & $P$ & $\mathrm{D}$ \\
\hline 8 & near- $2 n$ & NA & n.e. & G & G & G & 1.6 & 1.5 & NP & $A$ \\
\hline 9 & near $-2 n$ & NA & $95(2: 2), 5(3: 3)$ & n.e & n.e & n.e & 0.7 & 0.5 & NP & A \\
\hline 10 & near $-2 n$ & NA & $100(2: 2)$ & - & - & - & 0.7 & 0.5 & $P$ & $D$ \\
\hline 11 & near- $2 n$ & NA & $35(2: 2), 65(1: 3)$ & n.e & n.e & n.e & 1 & 2.3 & $P$ & $\mathrm{D}$ \\
\hline 12 & near-4n & A & $\begin{array}{c}51(1: 2), 30(2: 2), 19 \\
(1: 3)\end{array}$ & - & - & G & 0.5 & 0.6 & $P$ & $D$ \\
\hline 13 & near- $4 n$ & A & $\begin{array}{c}60(2: 2), 30(3: 3), 10 \\
(4: 4)\end{array}$ & - & - & - & 1.3 & 2.7 & $P$ & D \\
\hline
\end{tabular}

Thirteen representative cases drawn from the HSJD cohort analyzed by FISH, aCGH and Q-PCR of chromosome I. n.e = not evaluable results. MYCN amplification status: $\mathbf{N A}=$ not amplified, $\mathbf{A}=$ amplified. Disease status: $\mathbf{N P}=$ no disease progression, $\mathbf{P}=$ disease progression. Survival status: $\mathbf{A}=$ alive, $\mathbf{D}=$ dead. FISH: results are displayed as percentage of cells exhibiting the observed number of DNA probe signals, and exact number of signals for the DNA probes used: chromosome I (LSI Ip36 and LSI I q25 DNA probes) and chromosome 17(LSI I7pI3.I and CEP I7 DNA probes). Array $\mathrm{CGH}: \mathbf{p}$ and $\mathbf{q}=$ chromosome arms, cen. = centromeric; $\mathbf{G}=$ chromosome gain, $\mathbf{L}=$ chromosome loss. $\mathrm{Q}-\mathrm{PCR}$ : gene copy number fold changes are determined by the $\Delta \Delta \mathrm{C}_{\mathrm{T}}$ relative quantification method.

Gain of chromosome 17 is one of the most frequent genetic abnormalities observed in NBTs, and may involve either the entire chromosome or partial gain of the distal segment 17q21-qter [17]. Unbalanced translocations, characteristic of near diploid NBTs or tumours with structural rather than numerical chromosome aberrations, are thought to arise from DNA double strand breaks repaired erroneously, suggesting an impaired DNA maintenance or repair pathway [18]. On the other hand, abnormalities in the mitotic segregation of chromosomes are thought to underlie the numerical aberrations characteristic of neartriploid, good prognostic, NBTs. Both mechanisms define the type of aneuploidy behind each of the subgroups of NBTs, determining the kind of genetic aberrations as well as the biological behaviour of each NBT subtype.

Gene expression profiling of NBTs with different ploidy status, near-triploid or near-diploid/tetraploid, enabled us to identify distinct expression profiles associated with each subgroup. Interestingly, a statistically significant proportion of genes shown to be differentially expressed mapped to chromosomes described to be recurrently altered in NBTs, chromosomes 1 and 17 [17]. Chromosomal region specificity was also observed for these differentially expressed genes since the majority spread predominantly over the chromosomal regions $1 \mathrm{p} 36$ p22.1 and 17p13-17q21. Besides, over 90\% of these genes displayed higher expression levels in near-triploid tumours. Only two genes mapping to chromosome 17, MAC30 and NME1, exhibited a higher expression level in near-diploid/tetraploid NBTs. MAC30 gene encodes for a meningioma-associated protein, highly expressed in several types of tumours, but, with unknown clinicopathological and biological significance. The product of the NME1 gene, the nm23A protein, is a nucleoside diphosphate kinase, whose expression has been related to cell proliferative activity [19]. Whereas reduced expression of NME1 is associated with a high potential for metastasis in some tumour types, like breast cancer and melanoma, its expression is increased in aggressive NBTs [20].

Genome array CGH, together with FISH and Q-PCR results, confirmed the association of specific chromosomal abnormalities with each of the NBTs subgroups. Therefore, it is not unreasonable to assume that these specific chromosomal alterations are associated with the observed gene expression profiles. The highly significant and strikingly persistent chromosomal localization of the differentially expressed genes made us hypothesize about which transcriptional regulation mechanisms can under- 
Table 3: Results of FISH, aCGH, Q-PCR analyses of chromosome 17, displayed in relation to NBTs ploidy status

\begin{tabular}{|c|c|c|c|c|c|c|c|c|c|c|}
\hline \multirow[t]{2}{*}{$\begin{array}{c}\text { Case } \\
\text { Number }\end{array}$} & \multirow[t]{2}{*}{ Ploidy } & \multirow[t]{2}{*}{ MYCN } & \multirow{2}{*}{$\begin{array}{l}\text { FISH Chromosome } \\
\text { I7 } \\
\text { Cell \% (\# DNA probe } \\
\text { signals: LSI I7p I3.I: } \\
\text { CEP I7) }\end{array}$} & \multicolumn{3}{|c|}{ a CGH Chr. 17} & \multicolumn{2}{|c|}{$\begin{array}{l}\text { Q-PCR Gene copy No. } \\
\text { (fold change) }\end{array}$} & \multirow[t]{2}{*}{$\begin{array}{l}\text { Disease } \\
\text { Status }\end{array}$} & \multirow[t]{2}{*}{$\begin{array}{l}\text { Surviva } \\
\text { Status }\end{array}$} \\
\hline & & & & $\mathrm{P}$ & cen & $\mathrm{q}$ & $\begin{array}{l}\text { RUTBCI } \\
(|7 p| 3.3)\end{array}$ & $\begin{array}{c}\text { NMEI } \\
(|7 q 2|)\end{array}$ & & \\
\hline I & near-3n & NA & n.e & G & G & $\mathrm{G}$ & 2.3 & 2.5 & NP & $A$ \\
\hline 2 & near-3n & NA & 45 (2:2), 55 (3:3) & G & G & $\mathrm{G}$ & 1.5 & 1.5 & NP & A \\
\hline 3 & near-3n & NA & $45(2: 2), 55(3: 3)$ & G & $\mathrm{G}$ & $\mathrm{G}$ & 1.3 & $\mathrm{I} .4$ & NP & $A$ \\
\hline 4 & near-3n & NA & $30(2: 2), 70(3: 3)$ & G & $\mathrm{G}$ & $\mathrm{G}$ & 3.6 & 2.2 & NP & $A$ \\
\hline 5 & near-3n & NA & $50(2: 2), 50(3: 3)$ & $\mathrm{G}$ & G & G & 1.6 & 1.3 & NP & $A$ \\
\hline 6 & near-3n & NA & $50(2: 2), 50(3: 3)$ & $\mathrm{G}$ & G & $\mathrm{G}$ & 1.4 & 1.5 & NP & $A$ \\
\hline 7 & near- $2 n$ & NA & $\begin{array}{c}5(I: 1), 80(2: 2), 10 \\
(3: 3), 5(4: 4)\end{array}$ & n.e & n.e & n.e & 0.7 & 1.4 & NP & $A$ \\
\hline 8 & near- $2 n$ & NA & $33(1: 1), 66(2: 2)$ & - & - & - & 0.8 & 0.7 & $P$ & $D$ \\
\hline 9 & near- $2 n$ & $A$ & $\begin{array}{c}7(1: 1), 7(2: 1), 60(2: 2) \\
20(1: 2), 6(2: 3)\end{array}$ & - & - & $\mathrm{G}$ & 1.1 & 1.4 & $P$ & $\mathrm{D}$ \\
\hline 10 & near- $2 n$ & NA & $80(2: 2), 15(2: 3), 5(3: 3)$ & - & - & $\mathrm{G}$ & 1.2 & 1.5 & NP & $A$ \\
\hline 11 & near- $2 n$ & NA & $\begin{array}{c}28(1: 1) ; 11(2: 1), 56 \\
(2: 2), 5(3: 2)\end{array}$ & n.e & n.e & n.e & 1.1 & 0.9 & $P$ & $\mathrm{D}$ \\
\hline 12 & near-4n & $A$ & 45 (2:2); 55 (3:3) & - & - & $\mathrm{G}$ & I & 1.4 & $P$ & $D$ \\
\hline 13 & near-4n & $A$ & $\begin{array}{c}45(2: 2), 45(3: 3), 10 \\
(4: 4)\end{array}$ & G & G & G & 2.2 & 1.9 & $P$ & $\mathrm{D}$ \\
\hline
\end{tabular}

Thirteen representative cases drawn from the HSJD cohort analyzed by FISH, aCGH and Q-PCR of chromosome I7. n.e = not evaluable results. MYCN amplification status: $\mathbf{N A}=$ not amplified, $\mathbf{A}=$ amplified. Disease status: $\mathbf{N P}=$ no disease progression, $\mathbf{P}=$ disease progression. Survival status: $\mathbf{A}=$ alive, $\mathbf{D}=$ dead. FISH: results are displayed as percentage of cells exhibiting the observed number of DNA probe signals, and exact number of signals for the DNA probes used: chromosome I (LSI I 36 and LSI I q25 DNA probes) and chromosome I7(LSI I7pI3.I and CEP I7 DNA probes). Array CGH: $\mathbf{p}$ and $\mathbf{q}=$ chromosome arms, cen. = centromeric; $\mathbf{G}=$ chromosome gain, $\mathbf{L}=$ chromosome loss. $\mathrm{Q}-\mathrm{PCR}$ : gene copy number fold changes are determined by the $\Delta \Delta C_{T}$ relative quantification method.

lie these gene expression patterns. As a result of aneuploidy, cells possibly produce imbalanced expression of large sets of genes that are amplified or lost. Such gross imbalances would inevitably disrupt critical cellular circuits and destabilize regulatory pathways and cellular structures. It has been assumed that gene dosage effects may play a role in the pathogenesis of malignant diseases. Variations of the transcriptome due to alterations of the gene dosage have been described in vitro [21], in vivo [22] and in human pathologies such as trisomies 13 and 21 [23]. In our hands, when comparing gene expression levels with gene copy number of a set of differentially expressed genes located at chromosomes $1 \mathrm{p} 36$ and 17q13-q21, we observed a concordance between copy number and mean expression values in all those analyzed genes that displayed in the microarray analysis higher expression levels in near-triploid NBTs. In contrast, NME1 gene, as from microarray results, showed low expression values, close to the disomic reference sample expression, in near-triploid NBTs, and high fold increase in mRNA levels in near-diploid/tetraploid cases. NME1 gene has been identified as one of the MYCN targets. Correlation between MYCN overexpression and upregulation of NME1 expression has been reported both in NBTs and neuroblastoma cell lines [24]. In our experience, all MYCN amplified NBTs, displaying MYCN overexpression, as well as near-diploid cases with increased copy number of chromosome 17q, showed high NME1 expression levels. However, NME1 overexpression was also observed in 2 near-diploid MYCN single copy cases, with low MYCN expression and no $17 \mathrm{q}$ gain. This suggests that in NBTs NME1 gene expression is only partly dependent on gene copy number and MYCN expression, and therefore implies the existence of other mechanisms of NME1 transcriptional regulation.

Recently, we reported that clonal ploidy heterogeneity is present in virtually every single loco-regional, near-triploid NBT, and detected the existence of clonal DNA content heterogeneity and evolution $[25,26]$. In this report our results underscore the clonal heterogeneity of all NBTs, with a marked complexity in the near-diploid/tetraploid tumours. Furthermore, clonal variations reflected in the array CGH plots as copy-number alterations with varying $\log _{2}$ values, could unveil the presence of subpopulations emerged during tumour development. These cellular subpopulations are likely to be the cause of the high cell heterogeneity also observed in the FISH analyses. These 


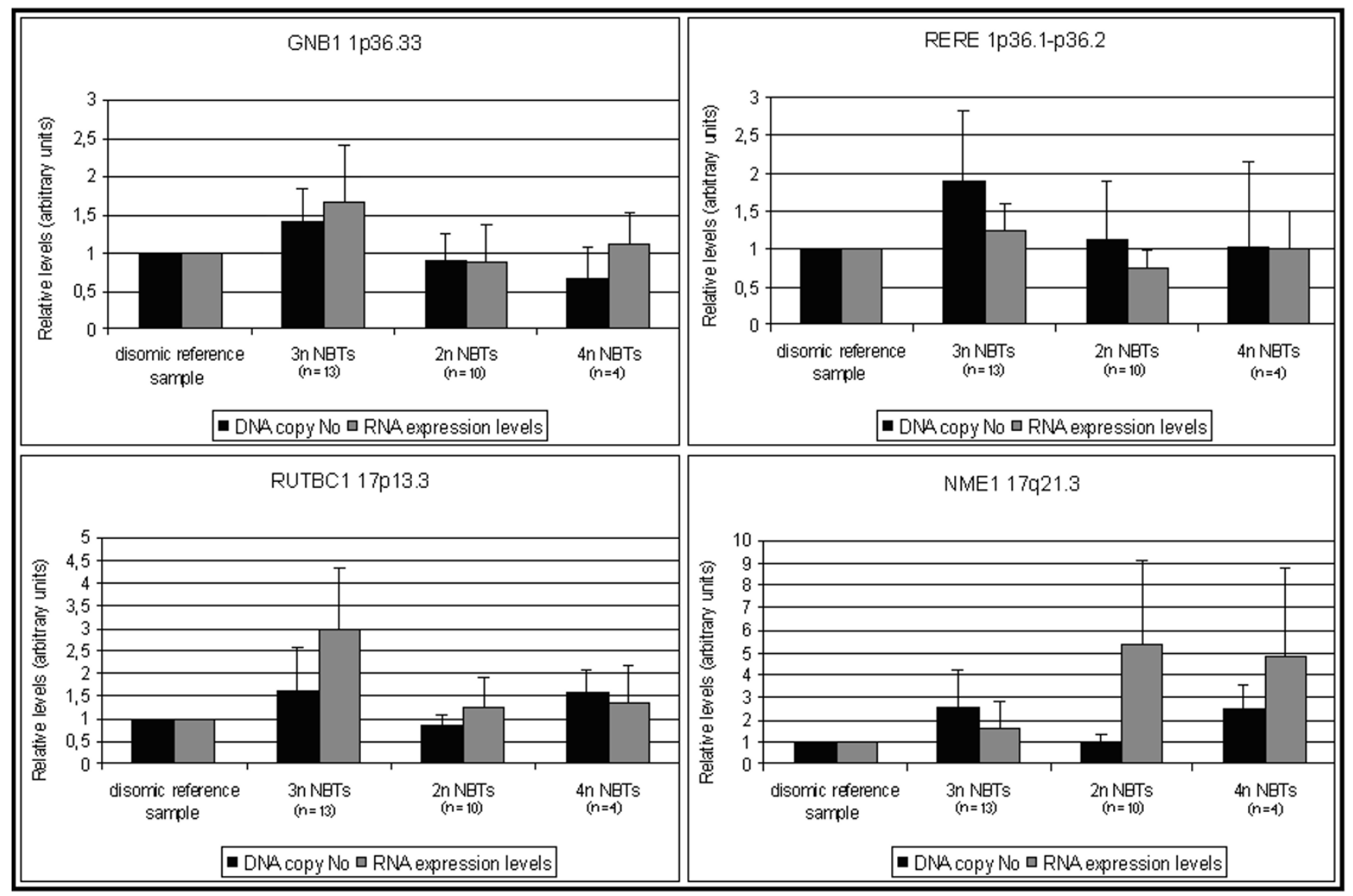

Figure 3

Comparison between DNA copy number and gene expression levels analyses. Gene expression levels and gene copy number are exhibited as mean values in accordance with NBT ploidy subgroups. Correlation between DNA gene copy number and expression levels was observed in those analyzed genes that displayed in the microarray analysis higher expression levels in near-triploid NBTs.

findings are important in emphasizing the cellular heterogeneity and karyotypic complexity (aneuploidy) generally associated with malignant tumours, but need a more detailed understanding of their significance.

\section{Conclusion}

We have found that NBTs with different cellular DNA content display specific transcriptional profiles suggesting that near-diploid/tetraploid and near-triploid NBTs result from two different mechanisms of aneuploidy driving tumourigenesis. A large number of the differentially expressed genes participate in cell differentiation pathways and map to specific chromosomal regions recurrently involved in unbalanced translocations, gains and losses in NBTs. Our results demonstrate that these specific genetic abnormalities are complex, heterogeneous, and translate into a gene expression profile that defines the biological behaviour of each type of NBT.

\section{Abbreviations}

NBTs: neuroblastic tumours; MIBG: Meta-iodobenzylguanidine; LOH: loss of heterozygosity; MSKCC: Memorial Sloan-Kettering Cancer Center, New York; HSJD: Hospital Sant Joan de Déu, Barcelona; Children's Oncology Group: COG; CT: computed tomography; INSS: International Neuroblastoma Staging System; INPC: International NB pathology committee; CNS: central nervous system; QPCR: Quantitative real-time polymerase chain reaction; aCGH: array-Comparative Genomic Hybridization; FISH: Fluorescence in situ hybridization.

\section{Competing interests}

The authors declare that they have no competing interests.

\section{Authors' contributions}

CL and JM are responsible for the initial conception and overall hypothesis of this study. CL, IG and JM are respon- 
Table 4: Chromosome 17 Fluorescence in situ Hybridization results of 40 NBTs obtained from MSKCC, displayed in relation to NBTs ploidy status

\begin{tabular}{|c|c|c|c|c|c|}
\hline Case Number & Ploidy & MYCN & FISH Chromosome I7 & Disease Status & Survival Status \\
\hline \multicolumn{6}{|c|}{ Cell \% (\# DNA probe signals: LSI I7p|3.I: CEP I7) } \\
\hline I & near-3n & NA & 23 (2:2), 44 (3:3), 33 (4:4) & NP & A \\
\hline 2 & near-3n & NA & $50(2: 2), 50(3: 3)$ & NP & A \\
\hline 3 & near-3n & NA & $16(2: 2), 41(3: 3), 43(4: 4)$ & NP & A \\
\hline 4 & near-3n & NA & 34 (2:2), 42 (3:3), 24 (4:4) & NP & A \\
\hline 5 & near-3n & NA & $33(2: 2), 50(3: 3), 17(4: 4)$ & $P$ & A \\
\hline 6 & near-3n & NA & $25(2: 2), 60(3: 3), 15(4: 4)$ & NP & $A$ \\
\hline 7 & near-3n & NA & 31 (2:2), 46 (3:3), $23(4: 4)$ & NP & A \\
\hline 8 & near-3n & NA & $35(2: 2), 52(3: 3), 13(4: 4)$ & NP & $A$ \\
\hline 9 & near-3n & NA & $23(2: 2), 54(3: 3), 23(4: 4)$ & NP & A \\
\hline 10 & near-3n & NA & $13(3: 3), 66(3: 4), 21(5: 5)$ & NP & $A$ \\
\hline 11 & near-3n & NA & $16(2: 2), 48(3: 3), 36(4: 4)$ & $P$ & A \\
\hline 12 & near-3n & NA & $35(2: 2), 58(3: 3), 7(4: 4)$ & NP & $A$ \\
\hline 13 & near-3n & NA & 46 (2:2), 24 (3:3), $30(4: 4)$ & NP & $A$ \\
\hline 14 & near-3n & NA & $22(3: 3), 62(4: 4), 16(4: 5)$ & $P$ & $\mathrm{D}$ \\
\hline 15 & near-3n & NA & $10(2: 2), 29(3: 3), 45(4: 4), 16(5: 5)$ & $P$ & $\mathrm{D}$ \\
\hline 16 & near- $2 n$ & NA & 5 (I:I), 65 (2:2), 5 (I:2), 10 (3:3), 5 (2:3), 5 (4:4), 5 (3:4) & $P$ & $\mathrm{D}$ \\
\hline 17 & near-2n & NA & $100(2: 2)$ & $P$ & $\mathrm{D}$ \\
\hline 18 & near- $2 n$ & NA & $95(2: 2), 5(3: 3)$ & $P$ & $\mathrm{D}$ \\
\hline 19 & near- $2 n$ & NA & 3I (CEP 2), 50 (CEP 3), 18 (CEP 4) & NP & A \\
\hline 20 & near- $2 n$ & NA & $25(1: 1), 75(2: 2)$ & $\mathrm{P}$ & $\mathrm{D}$ \\
\hline 21 & near- $2 n$ & NA & $100(2: 2)$ & $P$ & $\mathrm{D}$ \\
\hline 22 & near- $2 n$ & NA & n.e & $P$ & $\mathrm{D}$ \\
\hline 23 & near-2n & NA & I0 (CEP I), 40 (CEP 2), 38 (CEP 3), I2 (CEP 4) & $P$ & A \\
\hline 24 & near- $2 n$ & NA & $80(2: 2), 10(1: 2), 5(3: 3), 5(2: 2)$ & $P$ & A \\
\hline 25 & near-2n & NA & $100(2: 2)$ & $P$ & $\mathrm{D}$ \\
\hline 26 & near- $2 n$ & NA & $25(I: 1), 75(2: 2)$ & $\mathrm{P}$ & $\mathrm{D}$ \\
\hline 27 & near-2n & NA & $100(2: 2)$ & $\mathrm{P}$ & $\mathrm{D}$ \\
\hline 28 & near-2n & NA & 5 (2:1), $74(2: 2), 5(1: 2), 5(3: 3), 6(2: 3), 5(4: 4)$ & $P$ & $\mathrm{D}$ \\
\hline 29 & near- $2 n$ & NA & $10(2: 1), 70(2: 2), 15(1: 2), 5(3: 3)$ & $P$ & $\mathrm{D}$ \\
\hline 30 & near-2n & NA & n.e & $P$ & $\mathrm{D}$ \\
\hline 31 & near-2n & A & $20(2: 2), 32(3: 3), 12(4: 3), 20(4: 4), 16(3: 4)$ & NP & A \\
\hline 32 & near- $2 n$ & A & $40(1: 1), 60(2: 2)$ & NP & A \\
\hline 33 & near-2n & A & n.e & NP & A \\
\hline 34 & near- $2 n$ & A & $100(2: 2)$ & $P$ & A \\
\hline 35 & near- $2 n$ & A & 35 (2:2); 5 (3:2), $20(3: 3), 5(2: 3), 30(4: 4), 5(3: 4)$ & $P$ & $\mathrm{D}$ \\
\hline 36 & near- $2 n$ & A & $60(2: 2) ; 5(3: 2), 25(3: 3), 5(4: 3), 5(4: 4)$ & $P$ & $\mathrm{D}$ \\
\hline 37 & near- $2 n$ & A & $10(1: 1), 90(2: 2)$ & $\mathrm{P}$ & $\mathrm{D}$ \\
\hline 38 & near-4n & NA & 29 (2:2), 6 (3:3), 8 (4:3), 37 (4:4), 20 (3:4) & NP & A \\
\hline 39 & near- $4 n$ & NA & $49(2: 2), 37(3: 3), 9(2: 3), 5(3: 4)$ & NP & A \\
\hline 40 & near-4n & NA & 6 (2:2), $20(3: 3), 5$ (4:3), 46 (4:4), 18 (5:5), 5 (4:5) & $P$ & $A$ \\
\hline
\end{tabular}

n.e $=$ not evaluable results. MYCN amplification status: $\mathbf{N A}=$ not amplified, $\mathbf{A}=$ amplified. Disease status: $\mathbf{N P}=$ no disease progression, $\mathbf{P}=$ disease progression. Survival status: $\mathbf{A}=$ alive, $\mathbf{D}=$ dead. FISH: results are displayed as percentage of cells exhibiting the observed number of DNA probe signals, and exact number of signals for the DNA probes used: chromosome I (LSI Ip36 and LSI I q25 DNA probes) and chromosome I7(LSI I7pI3.I and CEP I7 DNA probes). Array CGH: $\mathbf{p}$ and $\mathbf{q}=$ chromosome arms, cen. = centromeric; $\mathbf{G}=$ chromosome gain, $\mathbf{L}=$ chromosome loss. Q-PCR: gene copy number fold changes are determined by the $\Delta \Delta C_{T}$ relative quantification method.

sible for the design of this manuscript, including the original draft and subsequent revisions and design of this manuscript. CdT assisted with the initial concept and was involved with the draft and revisions of this manuscript; provided guidance for many of the experiments. NKC and WLG are responsible for the procurement and cryopreser- vation of NBT tissue specimens derived from MSKCC. ER, IG, SA, HB and JM were responsible for the procurement and cryopreservation of NBT tissue specimens derived from the Spanish institutions. WLG and NP evaluated all tumour specimens for tumour staging classification and to assess tumour content. CL, NKC, WLG, and JM are 

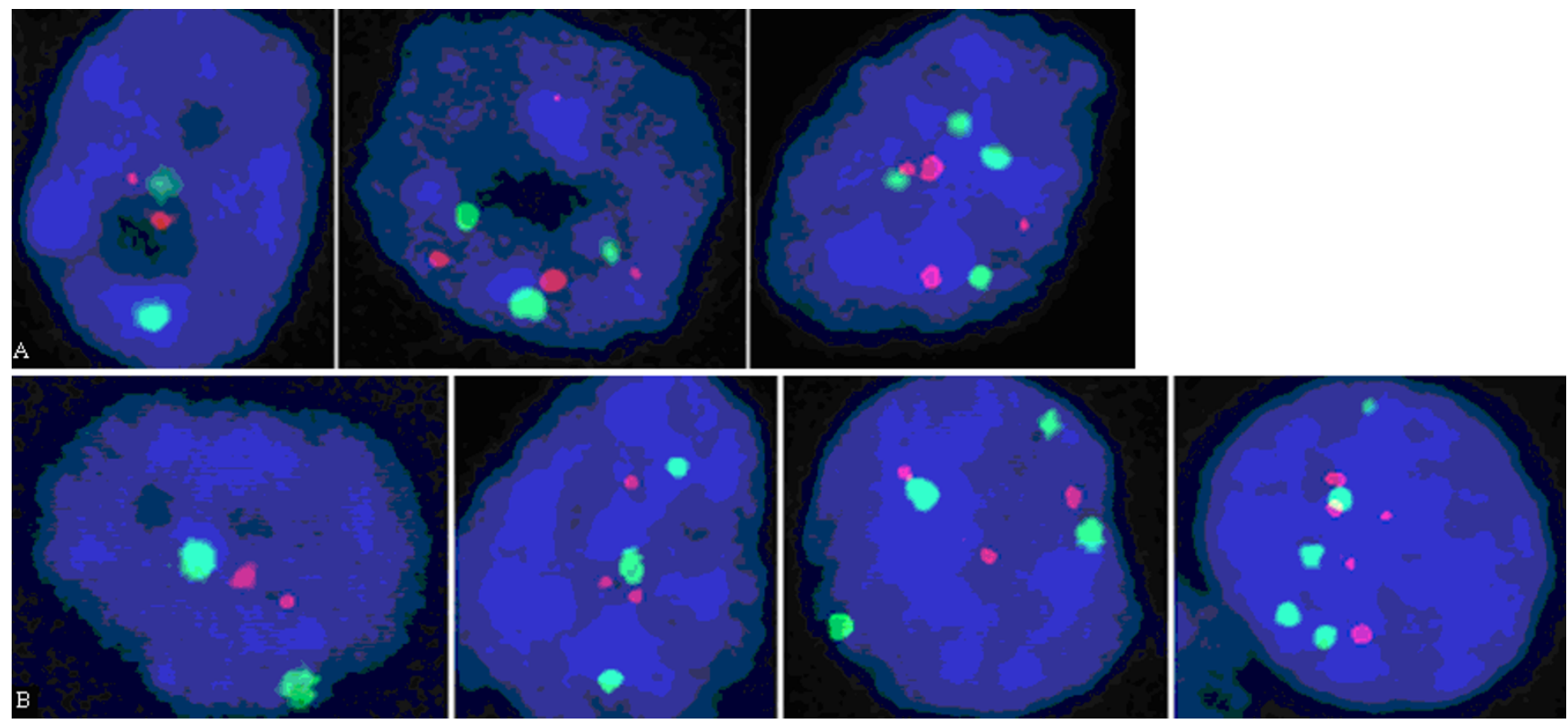

Figure 4

FISH analysis. Intra-tumoural cell heterogeneity, cancer cells exhibit different alterations of chromosome I7. FISH analysis using probes for chromosome 17 (red, LSI p53; green, CEP I7) showing different cellular populations within the same NBT in terms of probe signal numbers. In the panels are reported two representative NBT cases; A. near-triploid NBT; B. near-diploid case. Five signal cells in this sample were very rare populations (<5\%) and are not displayed in Table 3.

responsible for patient clinico-biological database management and for microarrays studies. NKC and WLG were involved in the drafting and revision of this manuscript. IG and CL are responsible for the quantitative PCR experiments. $\mathrm{CM}$ and EdA are responsible for the FISH and aCGH analyses and were also involved with the interpretation of data, draft and revision of this manuscript. ET performed the flow cytometry DNA analysis. CL, GD, JR and IG performed the statistical analysis and interpreta- tion of the data derived from all the samples. HB and SA assisted with valuable technical assistance for experiments associated with this manuscript. All were also involved in the drafting and revisions for this manuscript. All authors read and approved the final manuscript.

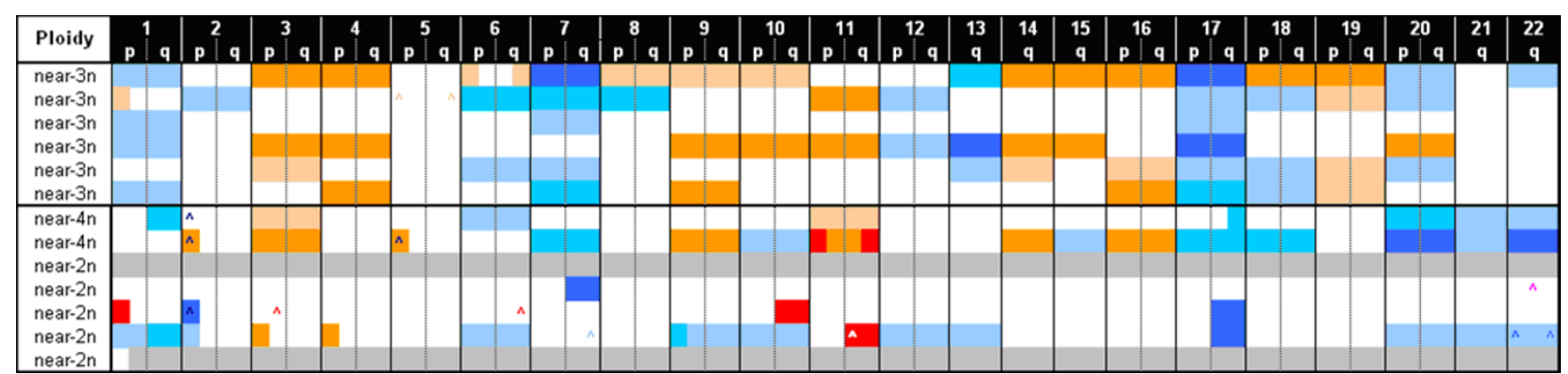

\section{Figure 5}

Array-Comparative Genomic Hybridization (aCGH) results of I 3 NBTs obtained from HSJD. Results are displayed according to tumour ploidy status. Chromosome alterations are visualized as a graded colour code adjusted to the log 2 rank of each individual plot assigned to define chromosomal segment alterations. Filled boxes: from orange to pink colour shades represent increasing chromosomal copy number gains, whereas, from light blue to dark blue colour shades indicate chromosome losses. White colour boxes represent no detected chromosome change. Grey colour boxes represent not evaluable results. 


\section{Additional material}

\author{
Additional file 1 \\ Quantitative Real-time Polymerase Chain Reaction Analysis. List of genes \\ analyzed to determine expression levels and DNA copy number of genes \\ located on chromosomes 1 and 17. \\ Click here for file \\ [http://www.biomedcentral.com/content/supplementary/1755- \\ 8794-1-36-S1.xls]

\section{Additional file 2} \\ Gene expression profiling of NBTs with different ploidy status. List of dif- \\ ferentially expressed genes identified applying different multiple testing \\ corrections. Differentially expressed genes are displayed according to \\ tumour ploidy and chromosomal location. A. List of 6 differentially \\ expressed genes [FDR $P<0,01] ; B$. List of 12 differentially expressed \\ genes [SDP $P<0,1] ; C$. List of 51 differentially expressed genes [FDR $P$ \\ $<0,05] ;$.D. List of 254 differentially expressed genes [FDR $P<0,1]$. \\ Click here for file \\ [http://www.biomedcentral.com/content/supplementary/1755- \\ 8794-1-36-S2.xls]

\section{Additional file 3} \\ Quantitative Real-time Polymerase Chain Reaction gene copy number \\ analysis and array CGH analysis results. $\boldsymbol{n} . \boldsymbol{e}=$ not evaluable results; $\boldsymbol{n} . \boldsymbol{d}$. \\ $=$ not done. MYCN amplification status: $N A=$ not amplified, $A=$ ampli- \\ fied. Disease status: $\mathbf{N P}=$ no disease progression, $\boldsymbol{P}=$ disease progression. \\ Survival status: $\mathbf{A}=$ alive, $\mathbf{D}=$ dead. $\mathbf{Q}-\mathbf{P C R}$ : gene copy number fold \\ changes are determined by the $\Delta \Delta C_{T}$ relative quantification method. \\ Array CGH: $\boldsymbol{p}$ and $\boldsymbol{q}=$ chromosome arms, cen. $=$ centromeric; $\mathbf{G}=$ chro- \\ mosome gain, $L=$ chromosome loss; - = no alteration observed. \\ Click here for file \\ [http://www.biomedcentral.com/content/supplementary/1755- \\ 8794-1-36-S3.xls]

\section{Additional file 4} \\ Array CGH images of NBT with different DNA content. A. Near-triploid \\ NBT; B. Near-diploid tumour and C. Near-tetraploid NBT. \\ Click here for file \\ [http://www.biomedcentral.com/content/supplementary/1755- \\ 8794-1-36-S4.jpeg]
}

\section{Acknowledgements}

This work was supported by: Career Development Award 200 I (to J. M.) from the American Society of Clinical Oncology (ASCO) and grants from the Spanish Ministry of Health (Instituto de Salud Carlos III, Fondo de Investigación Sanitaria, 2007; PI070286) (CL) and Spanish Society against Cancer (Asociación Española Contra el Cáncer, 2007) (JM and CL). The Developmental tumour biology laboratory, Hospital Sant Joan de Déu in Barcelona, is additionally supported by the Catalan government (AGAUR, Generalitat de Catalunya, 2005SGR00605; 2006FI00404), and the donation from Margarita del Pozo Fund. Supported in part by the National Cancer Institute grant CAI 06450 (NKC and WG), The Robert Steel Foundation (NKC), Hope Street Kids (NKC), and Katie's Find A Cure Fund (NKC) and the Government of Castilla y León (EdA).

We would like to thank Dr. R. Noguera, Department of Pathology, University of Valencia; and Dr. J. Alonso and Dr. P. García Miguel, Hospital La Paz,
Madrid, for kindly providing annotated samples, and T. Hernández (Centro de Investigación del Cáncer-IBMCC, Salamanca) for FISH hybridizations. Dr. J. San Miguel (Centro de Investigación del Cáncer-IBMCC, Salamanca) for kindly providing the BAC/PAC isolated DNA and Dr. JC Cigudosa (Centro Nacional de Investigaciones Oncológicas, Spain) for providing enriched medium-coverage set.

\section{References}

I. Brodeur GM, Sawada T, Tsuchida Y, Voûte PA: Neuroblastoma. Amsterdam: Elsevier Science; 2000.

2. Mora J, Gerald WL, Qin J, Cheung VNK: Evolving significance of prognostic markers associated with treatment improvement in patients with stage 4 neuroblastoma. Cancer 2002, 94:2756-65

3. Look AT, Hayes FA, Shuster J], Douglass EC, Castleberry RP, Bowman LC, Smith El, Brodeur GM: Clinical relevance of tumour cell ploidy and $\mathrm{N}$-myc gene amplification in childhood neuroblastoma. J Clin Oncol 1991, 9:58|-91.

4. Brodeur GM, Seeger RC, Schwab M, Varmus HE, Bishop JM: Amplification of $\mathbf{N}$-myc in untreated human neuroblastomas correlates with advanced disease stages. Science | 984, 224: | | 2 |-4.

5. Kaneko Y, Cohn SL: Ploidy and cytogenetics of neuroblastoma. In Neuroblastoma Edited by: Brodeur GM, Sawada T, Tsuchida Y, Voûte PA. Amsterdam: Elsevier Science; 2000:4I-56.

6. Pui CH, Raimondi SC, Dodge RK, Rivera GK, Fuchs LA, Abromowitch M, Look AT, Furman WL, Crist WM, Williams DL: Prognostic importance of structural chromosomal abnormalities in children with hyperdiploid ( $>\mathbf{5 0}$ chromosomes) acute lymphoblastic leukaemia. Blood 1989, 73:1963-67.

7. Kilpatrick SE, Teot LA, Geisinger KR, Martin PL, Shumate DK, Zbieranski N, Russell GB, Fletcher CD: Relationship of DNA ploidy to histology and prognosis in rhabdomyosarcoma. Cancer 1994, 74:3227-33.

8. Hedley DW: Flow cytometry using paraffin-embedded tissue: five years on. Cytometry 1989, 10:229-24I.

9. Mora J, Gerald WL, Cheung NK: Evolving significance of prognostic markers associated with new treatment strategies in neuroblastoma. Cancer Lett 2003, 197:।19-124.

10. Westfall PH, Young SS: Resampling-based Multiple Testing: Examples and Methods for p-value Adjustment. New York: John Wiley \& Sons Inc; 1993.

II. Benjamini Y, Hochberg Y: Controlling the False Discovery Rate: a Practical and Powerful Approach to Multiple Testing. Journal of the Royal Statistical Society B 1995, 57:289-300.

12. Vandesompele J, De Preter K, Pattyn F, Poppe B, Van Roy N, De Paepe A, Speleman F: Accurate normalization of real-time quantitative RT-PCR data by geometric averaging of multiple internal control genes. Genome Biology 2002, 3(7):research0034. I-0034.II.

13. Fischer M, Skowron M, Berthold F: Reliable transcript quantification by real-time transcriptase-polymerase chain reaction in primary neuroblastoma using normalization to averaged expression levels of the control genes HPRTI and SDHA. Journal of Molecular Diagnostics 2005, 7(I):89-96.

14. De Preter K, Speleman F, Combaret V, Lunec J, Laureys G, Eussen B, Francotte N, Board J, Pearson A, De Paepe A, Van Roy N, Vandesompele J: Quantification of MYCN, DDXI, and NAG gene copy number in neuroblastoma using a real-time quantitative PCR assay. Modern Pathology 2002, I 5(2): $159-166$.

15. Ladenstein R, Ambros IM, Pötschger U, Amann G, Urban C, Fink FM, Schmitt K, Jones R, Slociak M, Schilling F, Ritter J, Berthold F, Gadner $\mathrm{H}$, Ambros PF: Prognostic significance of DNA di-tetraploidy in neuroblastoma. Medical Pediatric Oncology 200I, 36(I):83-92.

16. Spitz R, Betts DR, Simon T, Boensch M, Oestreich J, Niggli FK, Ernestus $K$, Berthold F, Hero B: Favorable outcome of triploid neuroblastomas: a contribution to the special oncogenesis of neuroblastoma. Cancer Genetics and Cytogenetics 2006, 167:51-56.

17. Plantaz D, Mohapatra G, Matthay KK, Pellarin M, Seeger RC, Feuerstein BG: Gain of chromosome 17 is the most frequent abnormality detected in neuroblastoma by comparative genomic hybridization. Am J Pathol 1997, I 50:8I-9.

18. Janoueix-Lerosey I, Hupé P, Maciorowski Z, La Rosa P, Schleiermacher G, Pierron G, Liva S, Barillot E, Delattre O: Preferential 
occurrence of chromosome breakpoints within early replicating regions in neuroblastoma. Cell Cycle 2005, 4(I 2): | 842-6.

19. Keim D, Hailat N, Melhem R, Zhu XX, Lascu I, Veron M, Strahler J, Hanash SM: Proliferation-related expression of $\mathrm{pl} / \mathrm{nmm} 23$ nucleoside diphosphate kinase. J Clin Invest 1992, 89:919-24.

20. Valentijn LJ, Koppen A, van Asperen R, Root HA, Haneveld F, Versteeg R: Inhibition of a new differentiation pathway in neuroblastoma by copy number defects of $\mathrm{N}$-myc, Cdc42, and $\mathrm{nm} 23$ genes. Cancer Res 2005, 65:3136-45.

21. Kahlem P, Sultan M, Herwig R, Steinfath M, Balzereit D, Eppens B, Saran NG, Pletcher MT, South ST, Stetten G, Lehrach H, Reeves RH, Yaspo ML: Transcript level alterations reflect gene dosage effects across multiple tissues in a mouse model of down syndrome. Genome Res 2004, 14:1258-67.

22. FitzPatrick DR, Ramsay J, McGill NI, Shade M, Carothers AD, Hastie ND: Transcriptome analysis of human autosomal trisomy. Hum Mol Genet 2002, I I:3249-56.

23. Jones PA, Laird PW: Cancer epigenetics comes of age. Nat Genet 1999, 21:163-167.

24. Godfried MB, Veenstra M, v Sluis $P$, Boon $K, v$ Asperen R, Hermus MC, v Schaik BD, Voûte TP, Schwab M, Versteeg R, Caron HN: The $\mathrm{N}$-myc and c-myc downstream pathways include the chromosome I7q genes nm23-HI and nm23-H2. Oncogene 2002 , 21:2097-2101.

25. Mora J, Cheung NKV, Gerald WL: Genetic heterogeneity and clonal evolution in neuroblastoma. $\mathrm{Br} /$ Cancer 200I, 85: $182-189$.

26. Mora J, Lavarino C, Alaminos M, Cheung NK, Ríos J, de Torres C, Illei $P$, Juan $G$, Gerald WL: Comprehensive analysis of tumoural DNA content reveals clonal ploidy heterogeneity as a marker with prognostic significance in locoregional neuroblastoma. Genes, Chromosomes and Cancer 2007, 46:385-396.

\section{Pre-publication history}

The pre-publication history for this paper can be accessed here:

http://www.biomedcentral.com/1755-8794/1/36/prepub
Publish with Biomed Central and every scientist can read your work free of charge

"BioMed Central will be the most significant development for disseminating the results of biomedical research in our lifetime. "

Sir Paul Nurse, Cancer Research UK

Your research papers will be:

- available free of charge to the entire biomedical community

- peer reviewed and published immediately upon acceptance

- cited in PubMed and archived on PubMed Central

- yours - you keep the copyright
BioMedcentral 